\title{
Multifocal Subcutaneous and Muscular Tuberculosis in a Young Immunocompetent Man: A Case Report and Literature Review
}

\section{Tuberculose Muscular e Subcutânea Multifocal num Jovem Imunocompetente: Descrição de um Caso- Clínico e Revisão da Literatura}

\author{
João CABO $\rrbracket^{1}$, Luís MARTINS ${ }^{2}$, Ana TAVARES E CASTRO ${ }^{3}$, Fernando MALTEZ ${ }^{1}$ \\ Acta Med Port 2020 Jul-Aug;33(7-8):516-520 • https://doi.org/10.20344/amp.10706
}

\section{ABSTRACT}

Due to unfavorable conditions for survival and multiplication of Mycobacterium tuberculosis, muscle and soft tissue involvement is probably the rarest form of presentation of musculoskeletal tuberculosis, particularly without a clinically or radiologically apparent primary focus. As in other extrapulmonary forms of tuberculosis, its relative incidence is higher among immunocompromised patients. A progressive swelling is the most common complaint at presentation, which is otherwise mild and nonspecific. We present a case of multifocal (seven) subcutaneous and muscular tuberculous abscesses in a 29-year-old Indian patient who had no apparent underlying risk factors, nor any other organ involvement. Provisional diagnosis was initially made upon Mycobacterium tuberculosis complex nucleic acid detection in an aspirate of one of the collections and later confirmed by a positive culture on Lowenstein-Jensen medium. Two abscesses required aspiration and two others drained spontaneously. The patient responded well to nine months of anti-tuberculous therapy. An extensive review of the literature was made.

Keywords: Immunocompetence; Muscular Diseases; Mycobacterium tuberculosis; Pyomyositis; Tuberculosis

\section{RESUMO}

Devido à presença de condições adversas para a sobrevivência e multiplicação do Mycobacterium tuberculosis, o envolvimento dos músculos e tecidos moles representa a forma de apresentação mais rara da tuberculose músculo-esquelética, sobretudo na ausência de um foco primário clínica ou radiologicamente evidente. Tal como nas outras formas de tuberculose extra-pulmonar, a sua incidência relativa é mais elevada em indivíduos imunodeprimidos. A apresentação clínica, habitualmente uma tumefação de crescimento progressivo, é insidiosa e inespecífica. Os autores descrevem um caso de múltiplos (sete) abcessos tuberculosos subcutâneos e musculares num jovem indiano de 29 anos sem qualquer fator de risco subjacente nem envolvimento de outros órgãos. A deteção de ácidos núcleicos de Mycobacterium tuberculosis complex no conteúdo de uma das coleções colhido por aspiração permitiu um diagnóstico provisório, confirmado posteriormente por isolamento em cultura em meio de Lowenstein-Jensen. Dois dos abcessos necessitaram de drenagem por aspiração, enquanto outros dois drenaram de forma espontânea. O doente apresentou uma resposta favorável com nove meses de terapêutica anti-bacilar. Os autores completam o trabalho com uma extensa revisão sobre o tema.

Palavras-chave: Doenças Musculares; Imunocompetência; Mycobacterium tuberculosis; Piomiosite; Tuberculose

\section{INTRODUCTION}

Musculoskeletal tuberculosis (TB) occurs in $1 \%$ to $5 \%$ of all TB cases. ${ }^{1-4}$ Among these, muscle and soft tissue involvement is probably the rarest form of presentation, particularly when no primary focus is identified. ${ }^{3,5}$ Similarly to other extrapulmonary forms of TB, its relative incidence is higher among immunocompromised patients. ${ }^{4}$ Migratory patterns of population from endemic areas and the growing use of immunosuppressive drugs contribute to an increase in atypical presentations of the disease in developed countries. Diagnosis may be delayed due to nonspecific symptoms and a low index of suspicion. Although rare, cases of primary tuberculous pyomyositis affecting a single muscle have been reported. ${ }^{1,3,6}$ We present a rare case of multifocal subcutaneous and muscular tuberculous abscesses in a patient with no apparent underlying risk factors.

\section{CASE PRESENTATION}

A 29-year-old Indian male presented to our clinic with a gradually progressive painless swelling over the previous two months located on the right posterior cervical region. $\mathrm{He}$ associated the onset of the swelling with a massage provided by a friend. He also reported a post-traumatic persistent painful swelling on the lateral surface of his left leg over the previous three weeks. He complained of self-limited periods of dry cough for two months, but denied fever or night sweats. A two-kilogram weight loss from the onset of symptoms was reported.

His past medical and family history was unremarkable. Of note, he reported no TB disease in the past. The patient denied intra-muscular injections or intravenous drug use. $\mathrm{He}$ had been living in Portugal for four years and referred no recent visits to India.

On physical examination at admission, the patient

1. Infectious Diseases Department. Hospital de Curry Cabral. Lisboa. Portugal.

2. Pneumology Department. Hospital de Santa Maria. Lisboa. Portugal.

3. Centro de Diagnóstico Pneumológico Dr. Ribeiro Sanches. Lisboa. Portugal.

$\square$ Autor correspondente: João Cabo. jcabo44@hotmail.com

Recebido: 22 de abril de 2018 - Aceite: 13 de julho de 2018 | Copyright @ Ordem dos Médicos 2020 
appeared in good condition. His tympanic temperature was $37.8^{\circ} \mathrm{C}$ but no fever was registered during hospitalization. Vital signs were normal. His conjunctivae were slightly pale. There were no enlarged peripheral lymph nodes. A non-tender, painless, cystic swelling approximately $5 \times 4 \mathrm{~cm}$ in size was located on the lateral surface of the right posterior cervical region (Fig. 1A). It showed no adherence to the skin. Local temperature was normal and there were no overlying skin changes. A swelling with similar features measuring approximately $4 \times 6 \mathrm{~cm}$ was found on the left upper quadrant of the anterior abdominal wall, below the ribcage (Fig. 1B). A third swelling was located on the lower half of the lateral surface of his left leg. Fluctuation was palpable but, differently from the ones described above, it was tender, painful and the overlying skin was warm and red. A few days later, during hospitalization, a similar swelling appeared on the upper half of the lateral surface of the same leg, below the knee (Fig. 1C). The remaining physical examination was unremarkable.

The following tests had been performed before admission to our unit: normal chest $\mathrm{x}$-ray; sputum sample negative for acid-fast bacilli; ultrasound of the cervical swelling revealing a non-pure fluid collection located between the subcutaneous fat and the muscular layers.

Blood tests upon admission to our unit showed mild microcytic hypochromic anemia (hemoglobin: $10.5 \mathrm{mg} / \mathrm{L}$; mean corpuscular volume: $70.4 \mathrm{fL}$; mean corpuscular hemoglobin: $22.3 \mathrm{pg}$ ) and slightly elevated C-reactive protein $(35 \mathrm{mg} / \mathrm{L})$ and erythrocyte sedimentation rate (51 $\mathrm{mm} / \mathrm{h})$. Serum creatine phosphokinase (CPK) was not elevated. Renal function and white blood cell count were normal. Human immunodeficiency virus (HIV) screening was negative. Blood cultures (including in specialized medium for mycobacteria) yielded negative results. Human immunodeficiency virus (HIV) screening was negative. A whole body computed tomography (CT) scan showed multifocal (7) intramuscular and subcutaneous hypodense collections with a peripheral rim enhancement after contrast injection: (Figs. 2A, B e C) 1) right cervical region, in the splenius capitis muscle $(54 \times 34 \mathrm{~mm}) ; 2$ ) lateral side of the left half of the thoracic wall, in the latissimus dorsi muscle $(11 \times 16 \mathrm{~mm})$; 3) left flank of the anterior abdominal wall, between the external oblique and the transversus abdominis muscles $(42 \times 29 \times 72 \mathrm{~mm}) ; 4)$ left flank immediately above the iliac
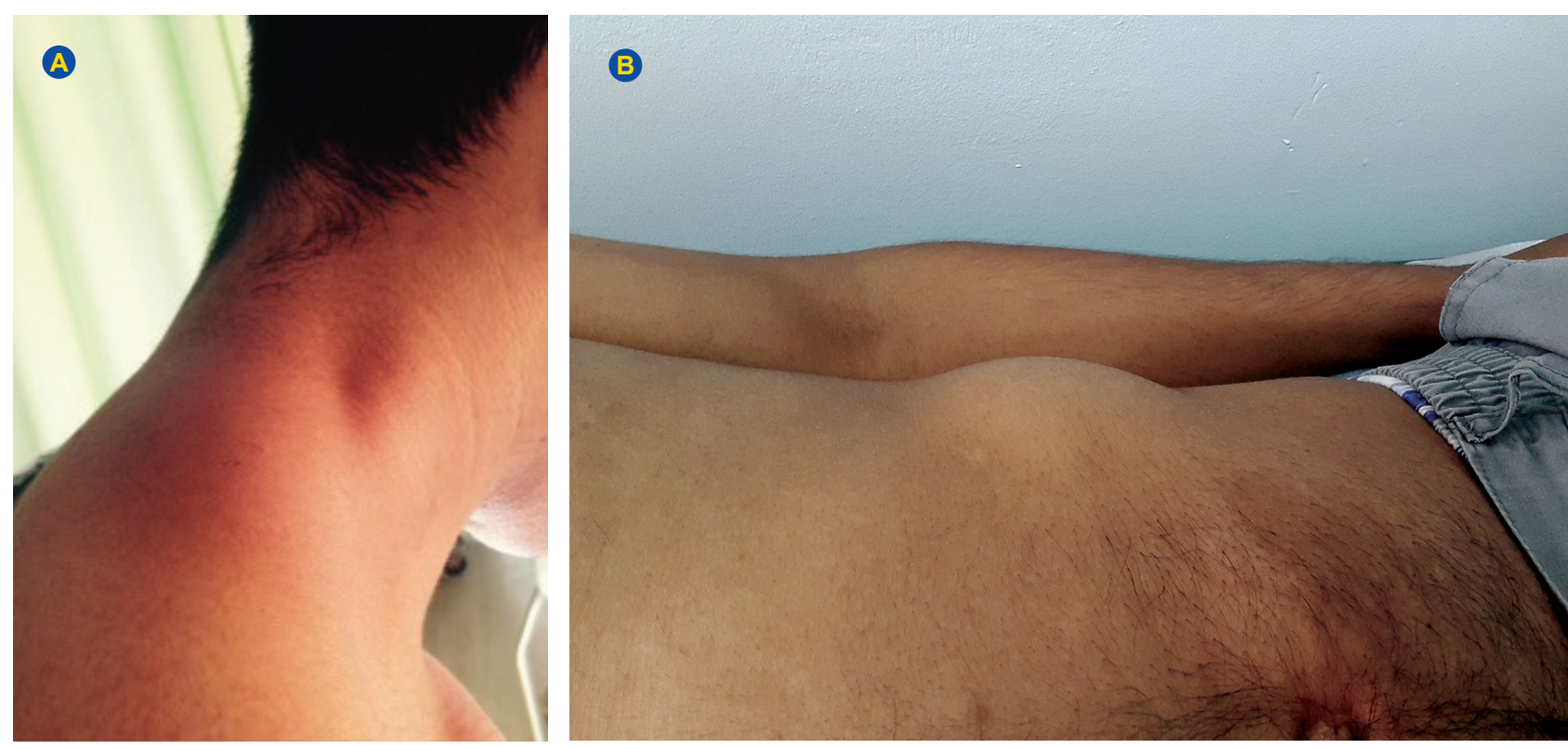

Figure 1 - Swellings apparent at physical examination. (A) Right posterior cervical region, at presentation; (B) Left upper quadrant of the anterior abdominal wall, at presentation; (C) Spontaneous drainage and healing of the two collections of the lower half of the left leg follow-up at 3.5 months.

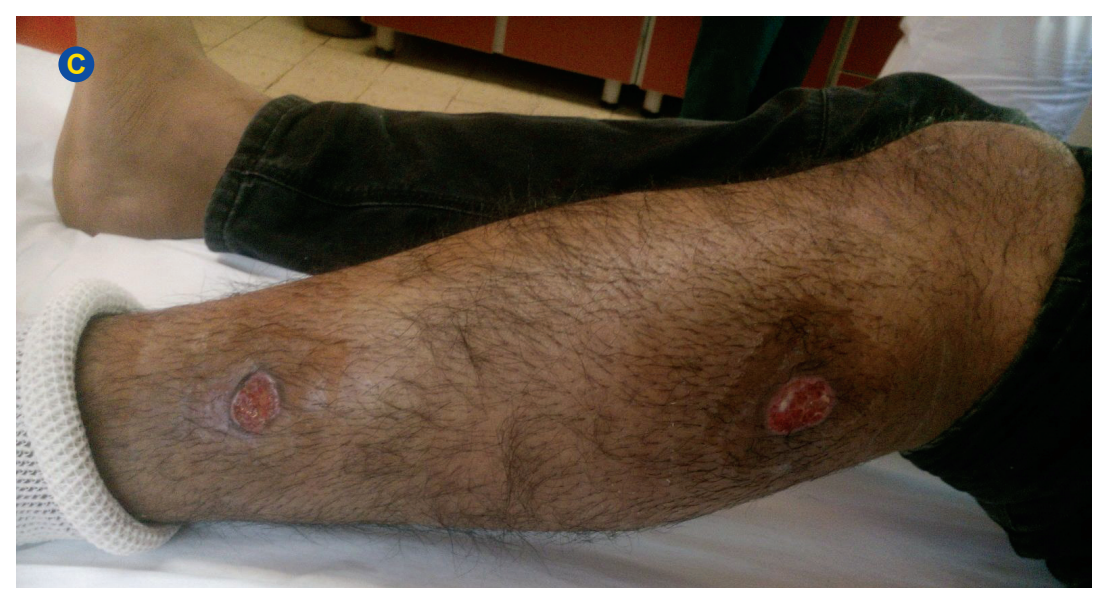



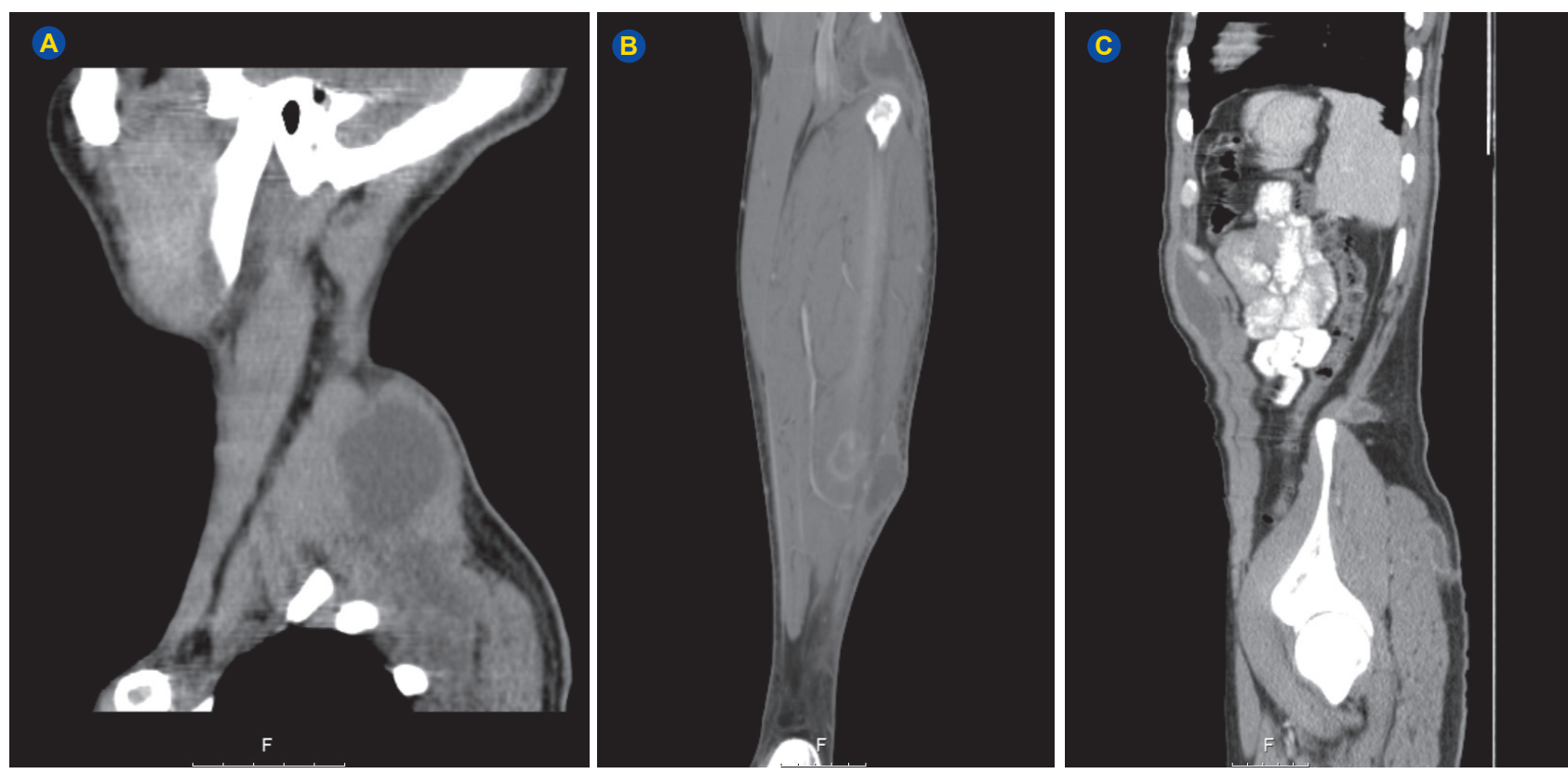

Figure 2 - Intra-muscular and soft tissue abscesses - CT scan at admission. (A) Posterior surface of the right cervical region; (B) Posterior surface of lower third of the left leg, in the soleus muscle, communicating with a bigger one located in the subcutaneous fat AND on the lateral surface of the upper third of the left leg, involving the proximal insertion of the plantaris muscle, communicating with a subcutaneous collection in the medial surface of the leg; (C) Left flank of the anterior abdominal wall, between the external oblique and the transversus abdominis muscles; left flank immediately above the iliac crest, in the subcutaneous tissue; left gluteal region, in the subcutaneous tissue.

crest, in the subcutaneous tissue $(23 \times 19 \times 25 \mathrm{~mm}) ; 5)$ left gluteal region, in the subcutaneous tissue $(41 \times 10 \times$ $67 \mathrm{~mm}$ ); 6) posterior surface of lower third of the left leg, in the soleus muscle $(24 \times 23 \times 4 \mathrm{~mm})$, communicating with a bigger one located in the subcutaneous fat $(90 \times 80 \times$ $10 \mathrm{~mm}) ; 7$ ) lateral surface of the upper third of the left leg, involving the proximal insertion of the plantaris muscle (32 $\times 27 \mathrm{~mm}$ ), communicating with a subcutaneous collection in the medial surface of the leg $(32 \times 10 \mathrm{~mm})$. No evidence of bone, synovial or tendon involvement was described. There were no lymphadenopathies or remarkable features in the lung parenchyma or pleural cavity. A homogeneous hepatomegaly $(18 \mathrm{~cm})$ was described. The spleen was normal.

An aspirate of the cervical collection was done, revealing a fluid with creamy appearance, 97300 white blood cells/ $\mathrm{LL}$, mostly polymorphonucleocytes, and elevated lactic dehydrogenase (15 $672 \mathrm{U} / \mathrm{L})$. No bacteria were found on smear examination using Gram and Ziehl-Neelsen stains. The culture under aerobic and anaerobic conditions was negative. However, Mycobacterium tuberculosis complex nucleic acid (DNA) was detected by polymerase chain reaction (PCR) assay, and the fluid culture on LowensteinJensen medium later yielded the microorganism. Sensitivity testing showed no phenotypic resistance to first-line drugs.

The patient was started on standard combination therapy for TB with isoniazid $(H)$, rifampin $(R)$, ethambutol $(E)$ and pyrazinamide $(Z)$, and was kept under regular followup. Both the abscesses on the left leg drained spontaneously, the one in the lower third (number 6) during hospitalization and the other (number 7 ) roughly one month and a half later (Fig. 1C). Wound dressing with activated charcoal was made regularly, and complete healing was observed from the sixth month of anti-TB therapy. Aspiration of the collection on the left upper quadrant of the abdominal wall (number 3 ) was done after three and a half months of therapy since it retained unchangeable dimensions. Interestingly, the fluid yielded a negative result after culture on Lowenstein-Jensen medium. The smaller collections (numbers 2, 4 and 5), which were unapparent on physical exam at admission, had disappeared in a follow-up CT scan performed by the end of the third month of anti-TB therapy. The patient completed 9 months of anti-TB therapy (2 HRZE ( 7 HR) and showed excellent clinical overall improvement. An $18 \mathrm{~kg}$ weight gain was observed. Laboratory changes at admission completely resolved. A CT scan obtained two months after the end of treatment confirmed complete healing of all collections. No clinical relapse has been observed in a 2-year follow-up period.

\section{DISCUSSION}

About $20 \%$ to $40 \%$ of newly diagnosed TB cases have extrapulmonary involvement, ${ }^{6}$ of which musculoskeletal forms represent a minority. ${ }^{1-4}$ Spondylitis, osteomyelitis and arthritis account for most of these cases. Uncommon presentations include primary bursitis (involving most commonly the great trochanteric and olecranon bursae), tenosynovitis (affecting most commonly the tendons of the wrist) and pyomyositis, probably the rarest of these entities. ${ }^{3,5}$ In a retrospective study, Soler et $\mathrm{al}^{7}$ estimated the incidence of primary tuberculous pyomyositis to be $0.0026 \%$. Muscle is an unfavorable site for survival and multiplication of Mycobacterium tuberculosis. Possible explanations include the high lactic acid content of the muscle, absence of reticulo-endothelial and lymphatic tissue, highly differentiated state of muscular 
tissue, and its rich blood supply. ${ }^{8}$ Muscle and soft tissue involvement, although rare, is a well recognized manifestation resulting from direct extension from an underlying bony or joint lesion or, rarely, from lymphohematogenous seeding in case of a primary focus elsewhere. ${ }^{4,5}$ Direct inoculation has also been described. ${ }^{5}$ Systemic immunosuppression (HIV infection, immunosuppressive therapies, chronic renal disease), collagen-vascular diseases or focal muscle frailty (past surgery or trauma, ischemia, foreign bodies) might represent underlying risk factors for tuberculous pyomyositis. $^{2,9,10}$ Nevertheless, soft tissue involvement without a clinically and/or radiologically apparent primary focus is extremely rare, particularly in immunocompetent patients. In our patient, multifocal muscle seeding likely resulted from hematogenous spread from an undetected healed focus. The neck massage and the left leg trauma possibly favored preexisting muscle collections to extend towards the overlying subcutaneous tissue. A similar phenomenon was described by Elshafie et al. ${ }^{2}$

A number of cases of tuberculous pyomyositis have been reported in the literature, not only in immunocompromised hosts, ${ }^{4,11-13}$ but also in patients with no identifiable underlying risk factors, both adults ${ }^{1-4,6,9,10,14}$ and children. ${ }^{15}$ In all cases, symptoms related to muscle involvement were the chief complaint, but in some primary pyomyositis could not be assumed because involvement of other structures

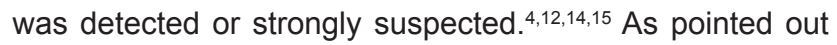
by Simopoulou et al, ${ }^{4}$ the large muscle groups of the pelvic girdle and thigh are the most commonly affected. Among immunocompetent patients single or neighboring muscle and subcutaneous involvement prevails. Primary multifocal involvement of different muscle groups without an underlying risk factor, as observed in our patient, has not been reported before, to our knowledge.

Clinical presentation is nonspecific and usually mild, which might pose diagnostic delays. Possible differential diagnosis to be considered include: intramuscular hydatid disease, bacterial pyomyositis (most commonly caused by $S$. aureus), chronic hematoma and soft tissue tumours such as sarcoma, myxoma or hemangioma. ${ }^{1,6}$ From the case reports included in the literature review, we conclude that features of sepsis are rather uncommon. A progressive swelling is the reason that most frequently prompts demand for healthcare services. Local pain and tenderness, although common, may not always be present. Constitutional symptoms occur in a minority of cases. Laboratory tests may show anemia, elevated ESR and CRP, leukocytosis and elevated CPK levels from muscle damage. Magnetic resonance imaging (MRI), with its superb contrast of soft tissue, is reported to be the imaging method of choice for defining the extent of the lesion and accessing the adjacent bones and joints. ${ }^{5,9,14}$ However, it has no diagnostic specificity regarding etiology, and collecting samples for microbiologic and/or histologic examination is recommended. ${ }^{5}$
Ziehl-Neelsen staining of pus or lesional biopsy may be negative because extrapulmonary specimens have few bacilli. Culture remains the gold standard for identification of the causative agent and is also important for determining drug susceptibility, but growth is usually not seen before the third week. Molecular methods have shown high sensitivity and may allow for an early diagnosis, ${ }^{4}$ such as in our patient, although false positives may occur.

No specific guidelines exist for the management of tuberculous pyomyositis. The cornerstone is early diagnosis and treatment with anti-TB drugs for a minimum of six months, although it seems reasonable to confirm radiological improvement before discontinuing therapy. Although pyogenic pyomyositis requires early surgical drainage, some authors suggest that, when dealing with tuberculous pyomyositis, a less radical approach can be adopted. ${ }^{10}$ In a clinically stable patient, the lesions may be first aspirated, cultured and treated with antituberculous drugs. Surgical drainage may be reserved for the following scenarios: compartment-syndrome like situations due to rapidly enlarging masses, failed aspiration, recurrence after aspiration, doubtful diagnosis or non-responsiveness. ${ }^{10}$ In most cases receiving timely diagnosis, appropriate anti-TB therapy and effective drainage, the prognosis for functional recovery is good. ${ }^{4}$ In our patient, the two larger abscesses required aspiration, two others drained spontaneously, and the three smaller ones responded to anti-TB treatment alone.

Due to migratory patterns of populations and the growing use of immunosuppressive drugs, atypical presentations of TB should always be considered even in developed countries, where TB incidence is low, particularly in patients coming from endemic regions.

\section{PROTECTION OF HUMANS AND ANIMALS}

The authors declare that the procedures were followed according to the regulations established by the Clinical Research and Ethics Committee and to the Helsinki Declaration of the World Medical Association.

\section{DATA CONFIDENTIALITY}

The authors declare having followed the protocols in use at their working center regarding patients' data publication.

\section{PATIENT CONSENT}

Obtained.

\section{CONFLICTS OF INTEREST}

All authors report no conflict of interest.

\section{FUNDING SOURCES}

This research received no specific grant from any funding agency in the public, commercial, or not-for-profit sectors. 
1. Perez-Alonso AJ, Husein El-Ahmed H, Duran CP. Isolated muscle tuberculosis. Med Mal Infect. 2011;41:559-64.

2. Elshafie KT, Al-Hinai MM, Al-Habsi HA. A massive tuberculosis abscess at the Erector Spinae muscles and subcutaneous tissues in a young man. Sultan Qaboos Univ Med J. 2013;13:601-5.

3. Sen RK, Tripathy SK, Deivaraju C. Isolated focal pyomyositis of teres minor: an unusual presentation of tuberculosis. Acta Orthop Traumatol Turc. 2011;45:276-9.

4. Simopoulou T, Varna A, Dailiana ZH, Katsiari CG, Alexiou I, Basdekis G, et al. Tuberculous pyomyositis: a re-emerging entity of many faces. Clin Rheumatol. 2016;35:1105-10.

5. Abdelwahab IF, Bianchi S, Martinoli C; Klein M, Hermann G. Atypical extraspinal musculoskeletal tuberculosis in immunocompetent patients: part II, tuberculous myositis, tuberculous bursitis, and tuberculous tenosynovites. J Am Coll Radiol. 2006;57:278-86.

6. Modi MA, Mate AD, Nasta AM, Gvalani AK. Primary tuberculous pyomyositis of quadriceps femoris in an immunocompetent individual. Case Rep Infect Dis. 2013;2013:723879.

7. Soler R, Rodríguez $\mathrm{E}$, Remuiñán $\mathrm{C}$, Santos $\mathrm{M}$. MRI of musculoskeletal extraspinal tuberculosis. J Comput Assist Tomogr. 2001;25:177-8.
8. Kim JY, Park YH, Choi KH, Park SH, Lee HY. MRI of tuberculous pyomyositis. J Comput Assist Tomogr. 1999;23:454-7.

9. Daghfous A, Bouzaidi K, Marhoul L. Pyomyosite tuberculeuse primitive chez une patiente immunocompétente: à propos d'un cas. Pan Afr Med J. 2014;19:200.

10. Narang S. Tuberculous pyomyositis of forearm muscles. Hand 2009;4:88-91.

11. Hughes $\mathrm{T}$, Booth $\mathrm{J}$. Tuberculous pyomyositis in a renal transplant recipient. Clin Kidney J. 2012;5:367-8.

12. Chen WL, Lin YF, Tsai WC, Tsao YT. Unveiling tuberculous pyomyositis: an emerging role of immune reconstitution inflammatory syndrome. Am J Emerg Med. 2009;27:251.

13. Mootsikapun $P$, Mahakkanukrauh $A$, Suwannaroj $S$, Nanagara R. Tuberculous pyomyositis. J Med Assoc Thai. 2003;86:477-81.

14. Batra $S, A b$ Naell $M$, Barwick $C$. Tuberculous pyomyositis of the thigh masquerading as malignancy with concomitant tuberculous flexor tenosynovitis and dactylitis of the hand. Singap Med J. 2007;48:1042.

15. Chewoolkar V, Bichile L, Patel H. Pyomyositis with multifocal osteomyelitis - an uncommon presentation of skeletal tuberculosis. J Assoc Physicians India. 2009;57:706. 